\title{
ПРОГНОЗ ЗЕМЛЕПОЛЬЗОВАНИЯ В РОССИИ
}

Мазуркин П.М., д.т.н., проф., акад. РАЕ и РАЕН, член ЕАЕ, Поволжский ГТУ, Йошкар-Ола, пл. Ленина, 3, kaf_po@mail.ru

Введение. По данным [1] были выявлены тренды. Однако они без дополнения волновыми составляющими не позволяют рассчитать прогнозы по динамике землепользования.

Методология факторного анализа изложена в [2-7], а программная среда для статистического моделирования дана в [5].

Цель статьи - показать метод прогнозирования динамики площади сельскохозяйственных угодий (СХУ).

Исходные данные. По данным за 2011 год [1] дополнительно были введены удельные показатели: доли пашни, сенокосов и пастбищ, залежей по отношению к площади угодий.

Результаты моделирования. В таблице 1 в матричной форме даны параметры моделей.

Таблица 1 - Параметры закономерностей динамики площади земель

\begin{tabular}{|c|c|c|c|c|c|c|c|c|c|}
\hline & \multicolumn{8}{|c|}{$y_{i}=a_{1 i} x^{a_{2 i}} \exp \left(-a_{3 i} x^{a_{4 i}}\right) \cos \left(\pi x /\left(a_{5 i}+a_{6 i} x^{a_{7 i}}\right)-a_{8 i}\right)$} & \multirow{3}{*}{$\begin{array}{l}\text { Коэфф } \\
\text { коррел }\end{array}$} \\
\hline & \multicolumn{4}{|c|}{ Амплитуда колебания } & \multicolumn{4}{|c|}{ Полупериод и сдвиг колебания } & \\
\hline & $a_{1 i}$ & $a_{2 i}$ & $a_{3 i}$ & $a_{4 i}$ & $a_{5 i}$ & $a_{6 i}$ & $a_{7 i}$ & $a_{8 i}$ & \\
\hline \multicolumn{10}{|c|}{ Все сельскохозяйственные угодья $S_{C X Y}$, тыс. га } \\
\hline 1 & $2,22404 \mathrm{e} 5$ & 0 & 1,31278e-6 & 2,64630 & 0 & 0 & 0 & 0 & \multirow{3}{*}{0,9989} \\
\hline 2 & $-6,42815 \mathrm{e} 5$ & 6,01612 & 10,78470 & 0,27099 & 0 & 0 & 0 & 0 & \\
\hline 3 & 617,79865 & 0,55124 & 0,41495 & 1 & 0,53239 & 0,096651 & 1 & 3,47125 & \\
\hline \multicolumn{10}{|c|}{ Площадь пашня $S_{\Pi}$, тыс. га } \\
\hline 1 & $1,32260 \mathrm{e} 5$ & 0 & 0,00077443 & 1,27941 & 0 & 0 & 0 & 0 & \multirow{3}{*}{0,9998} \\
\hline 2 & $-8,26382 \mathrm{e} 5$ & 9,56356 & 13,08911 & 0,31423 & 0 & 0 & 0 & 0 & \\
\hline 3 & $-8,42080$ & 2,33906 & 0,21681 & 1 & $-3,13521$ & 4,40866 & 0,094 & $6-0,20179$ & \\
\hline \multicolumn{10}{|c|}{ Площадь сенокосов и пастбищ $S_{C п}$, тыс. га } \\
\hline 1 & 87708,983 & 0 & $-0,00065214$ & 1,15256 & 0 & 0 & 0 & 0 & \multirow{3}{*}{0,9984} \\
\hline 2 & $1,93921 \mathrm{e} 5$ & 12,68072 & 15,63669 & 0,33858 & 0 & 0 & 0 & 0 & \\
\hline 3 & $-2636,5270$ & 1,01396 & 1,02524 & 1 & 1,92755 & 0 & 0 & 1,32038 & \\
\hline \multicolumn{10}{|c|}{ Площадь залежи $S_{3}$, тыс. га } \\
\hline 1 & 297,63407 & 0 & 0,0010611 & 2,24127 & 0 & 0 & 0 & 0 & \multirow{4}{*}{0,9998} \\
\hline 2 & $9,66199 \mathrm{e}-7$ & 8,06967 & 16,38819 & 0,24529 & 0 & 0 & 0 & 0 & \\
\hline 3 & 77,52106 & 0,16843 & 0 & 0 & 0,50768 & 0,052882 & 1 & 5,30496 & \\
\hline 4 & 0,00053826 & 4,05427 & 0 & 0 & 1,76029 & 0 & 0 & 4,22099 & \\
\hline \multicolumn{10}{|c|}{ Доля в СХУ пашни, \% } \\
\hline 1 & 59,44648 & 0 & 0,00037776 & 1,60345 & 0 & 0 & 0 & 0 & \multirow{2}{*}{0,9998} \\
\hline 2 & $-0,0022225$ & 4,47494 & 0,33644 & 1,00375 & 0 & 0 & 0 & 0 & \\
\hline
\end{tabular}




\begin{tabular}{|c|c|c|c|c|c|c|c|c|c|}
\hline \multicolumn{3}{|c|}{\begin{tabular}{|l|l|l|}
3 & $-7,49756 e-1223,00314$ \\
\end{tabular}} & 6,13611 & 0,68299 & 1,21977 & 0,010460 & 1,55180 & 6,14356 & \\
\hline \multicolumn{10}{|c|}{ Доля в СХУ сенокосов и пастбищ, \% } \\
\hline 1 & 39,27728 & 0 & $-0,0023260$ & 1 & 0 & 0 & 0 & 0 & \multirow{3}{*}{0,9993} \\
\hline 2 & $9,23371 \mathrm{e}-5$ & 5,93334 & 0,44875 & 1 & 0 & 0 & 0 & 0 & \\
\hline 3 & 0,40555 & 0 & 0,24017 & 0,97695 & 1,04596 & 0,25856 & 0,73741 & 5,34632 & \\
\hline \multicolumn{10}{|c|}{ Доля в СХУ залежи, \% } \\
\hline 1 & 0,00043825 & 0 & $-1,23877$ & 0,53914 & 0 & 0 & 0 & 0 & \multirow{4}{*}{0,9997} \\
\hline 2 & 0,047183 & 1,77512 & 0,014697 & 1,55402 & 0 & 0 & 0 & 0 & \\
\hline 3 & 0,19370 & 0 & 0,30501 & 1 & 2.90371 & 0 & 0 & 0,61674 & \\
\hline 4 & $-0,00073312$ & 2,87671 & 0,22771 & 1 & 4,43388 & $-0,062964$ & 1 & $-1,35243$ & \\
\hline
\end{tabular}

Динамика СXУ. Графики по параметрам модели из таблицы 1 приведены ан рисунке 1.

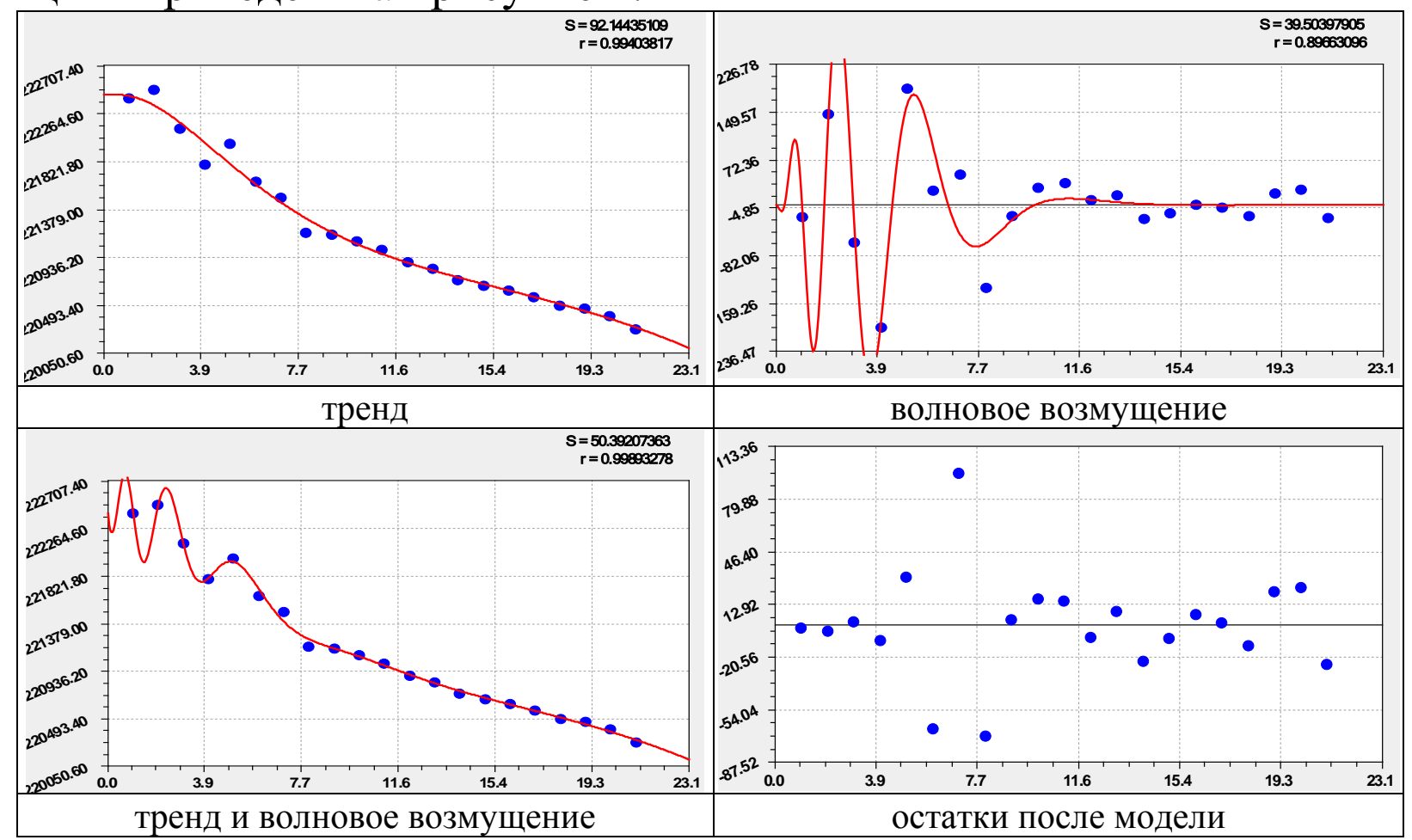

Рис. 1. Графики динамики всех сельскохозяйственных угодий с 1990 по 2011 гг.

Трехчленное уравнение показывает, что волна на рисунке 1 была в прошлом, поэтому на прогноз она не влияет.

В связи с этим прогнозная модель будет равна

$$
\begin{aligned}
& S_{C X Y}^{n p}=2,22404 \cdot 10^{5} \exp \left(-1,31278 \cdot 10^{-6} t^{2,64630}\right)- \\
& -6,42815 \cdot 10^{5} t^{6,01612} \exp \left(-10,7847 t^{0,227099}\right) .
\end{aligned}
$$

Динамика пашни. Прогнозная модель (рис. 2) характеризуется уравнением вида

$$
\begin{gathered}
S_{I I}^{n p}=1,32260 \cdot 10^{5} \exp \left(-0,00077443 t^{1,27941}\right)- \\
-8,26382 \cdot 10^{5} t^{9,56356} \exp \left(-13,08911 t^{0,31423}\right)-A \cos (\pi t / p+0,20179), \\
A=8,42080 t^{2,33906} \exp (-0.21681 t), p=-3,13521+4,40866 t^{0,094025} .
\end{gathered}
$$




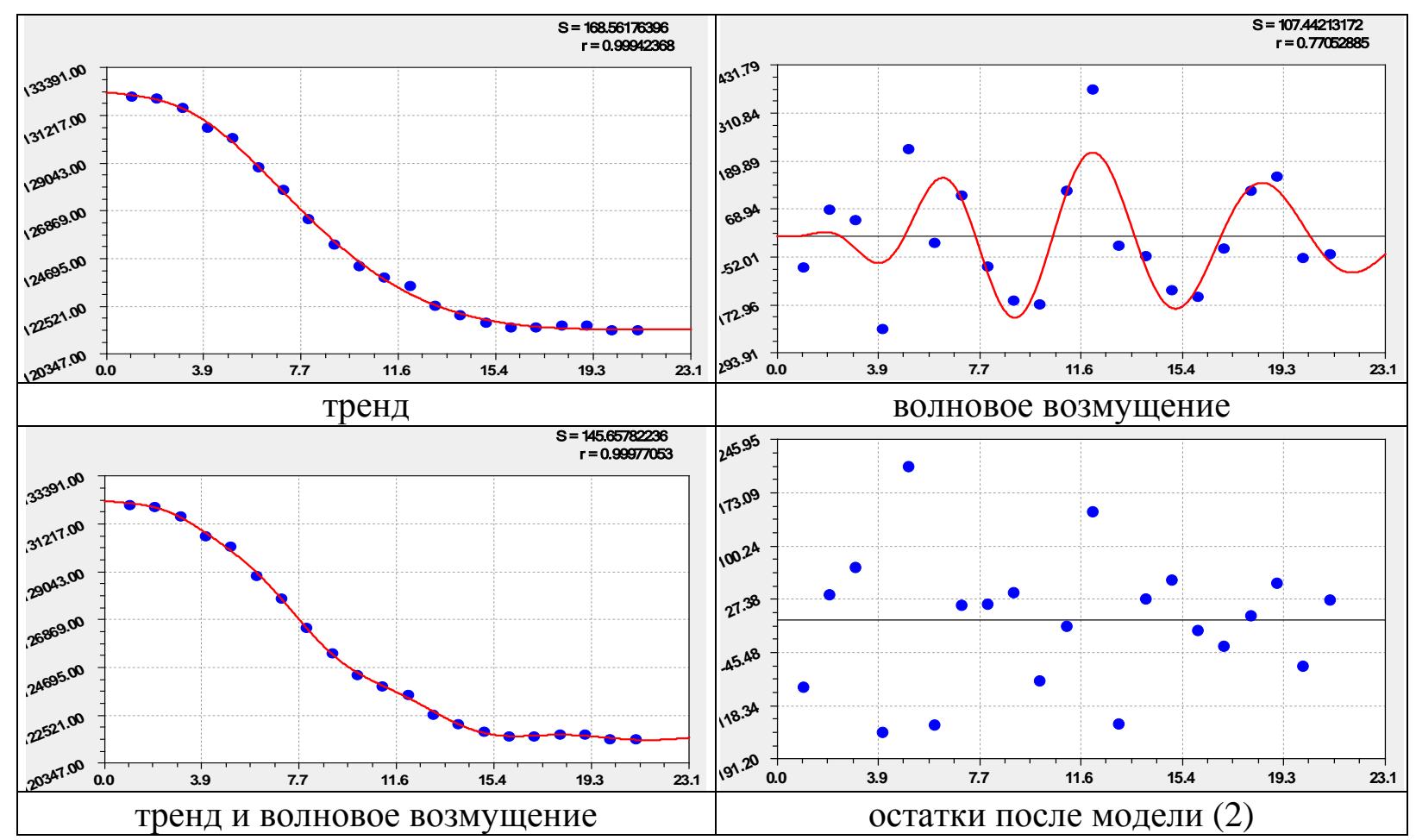

Рис. 2. Графики динамики пашни в России с 1990 по 2011 гг.

Динамика сенокосов и пастбищ. Она дается (рис. 3) так:

$$
\begin{gathered}
S_{C \Pi}^{n p}=87708,983 \exp \left(0,00065214 t^{1,15256}\right)+ \\
+1,93921 \cdot 10^{5} t^{12,68072} \exp \left(-15,63669 t^{0,33258}\right) .
\end{gathered}
$$

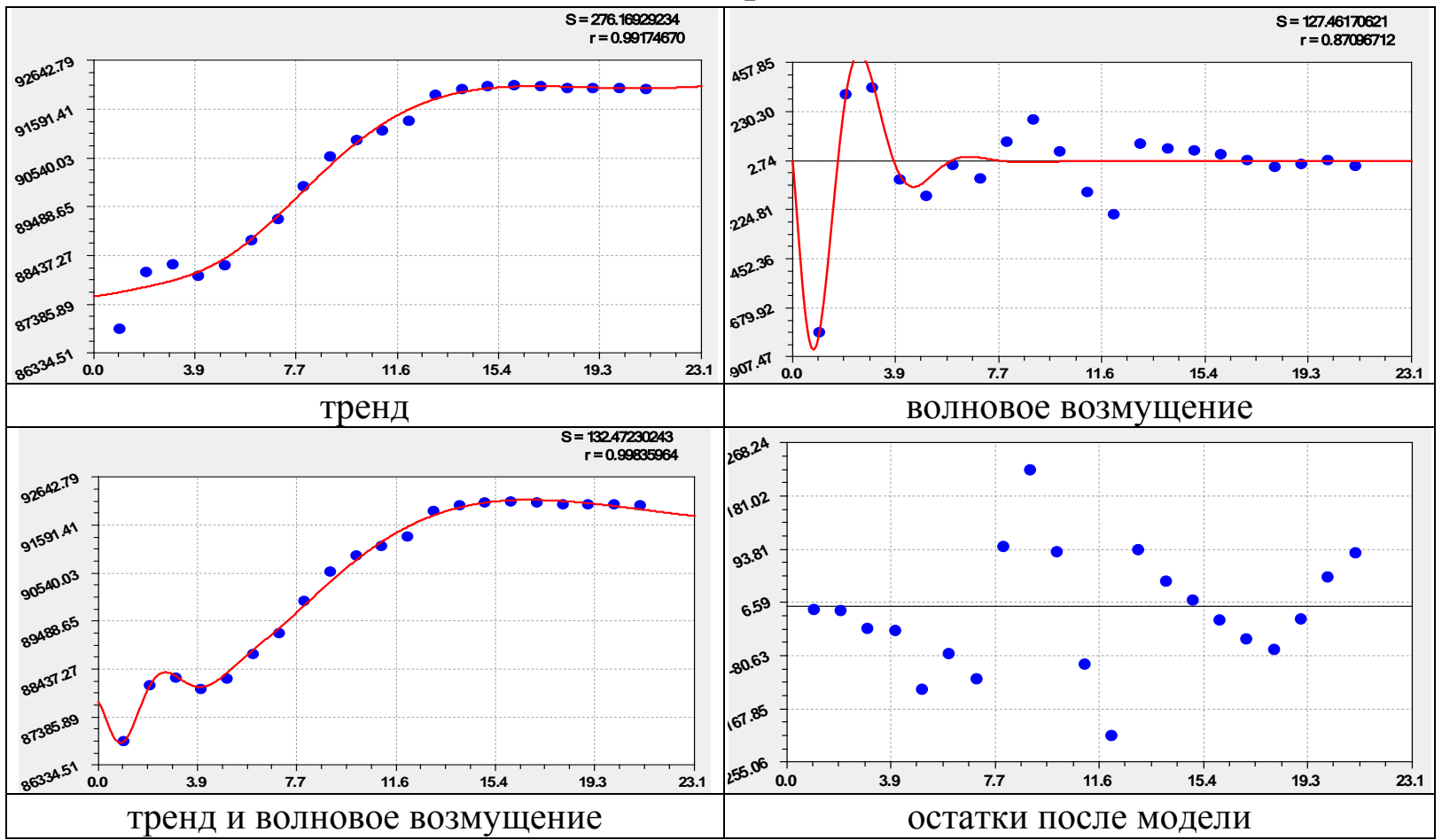

Рис. 3. Графики динамики площади сенокосов и пастбищ в России с 1990 по 2011 гг.

Динамика залежи. Для прогноза имеет (рис. 4) формулу, две составляющие которой влияют на горизонт прогноза 


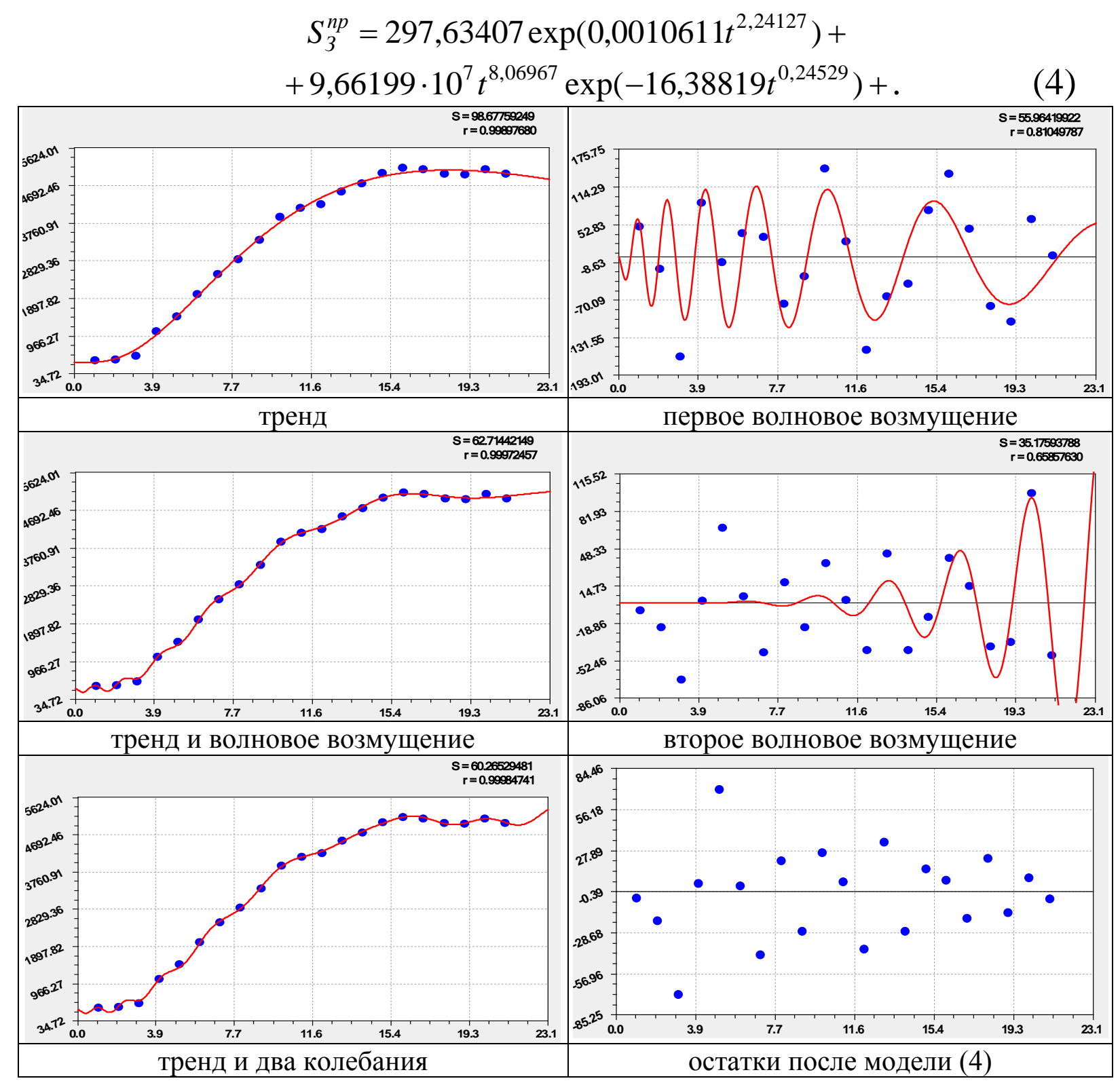

Рис. 3. Графики динамики площади залежи в России с 1990 по 2011 гг.

Результаты прогноза. Они приведены в таблице 2.

Прогнозная динамика площади сельскохозяйственных угодий Российской Федерации с 2012 по 2030 годы (с землями личного пользования)

\begin{tabular}{|c|c|c|c|c|c|c|c|c|}
\hline \multirow[b]{2}{*}{ Год } & \multirow[b]{2}{*}{$\begin{array}{r}\text { Время } \\
t, \text { лет }\end{array}$} & \multirow{2}{*}{$\begin{array}{c}\text { Сельско- } \\
\text { хозяйств. } \\
\text { угодья } S_{C X y}\end{array}$} & \multicolumn{3}{|c|}{ в том числе, тыс. га } & \multicolumn{3}{|c|}{ Доля в СХУ, \% } \\
\hline & & & $\begin{array}{c}\text { пашня } \\
S_{\Pi}\end{array}$ & $\begin{array}{c}\text { сенокосы } \\
\text { и пастб. } S_{C \Pi}\end{array}$ & $\begin{array}{c}\text { залежь } \\
\mathrm{S}_{3}\end{array}$ & $\begin{array}{c}\text { пашня } \\
\alpha_{\Pi}\end{array}$ & $\begin{array}{c}\text { сенокосы } \\
\text { и пастб. } \alpha_{C п}\end{array}$ & $\begin{array}{c}\text { залежь } \\
\alpha_{3}\end{array}$ \\
\hline \multicolumn{9}{|c|}{ Основание прогноза } \\
\hline 1990 & 0 & 222409.2 & 132304.2 & 87899.5 & 347.2 & 59.49 & 39.52 & 0.16 \\
\hline .. & $\ldots$ & $\ldots$ & $\ldots$ & $\ldots$ & $\ldots$ & $\ldots$ & $\ldots$ & . \\
\hline 2011 & 21 & 220272.1 & 121444.9 & 92028.3 & 4996.9 & 55.13 & 41.78 & 2.27 \\
\hline \multicolumn{9}{|c|}{ Горизонт прогноза } \\
\hline 2012 & 22 & 194215,7 & 121617,3 & 91868,8 & 5291,4 & 55,08 & 41,78 & 2,21 \\
\hline 2013 & 23 & 192790,0 & 121592,5 & 91800,0 & 5079,0 & 55,02 & 41,80 & 2,17 \\
\hline
\end{tabular}




\begin{tabular}{|l|l|l|l|l|l|l|l|l|}
\hline 2014 & 24 & 191414,4 & 121542,4 & 91737,4 & 5143,4 & 54,95 & 41,83 & 2,13 \\
\hline 2015 & 25 & 190089,2 & 121517,6 & 91683,3 & 5236,6 & 54,85 & 41,87 & 2,10 \\
\hline 2016 & 26 & 188814,2 & 121533,8 & 91639,3 & 4815,9 & 54,74 & 41,92 & 2,07 \\
\hline 2017 & 27 & 187589,0 & 121567,4 & 91606,3 & 5515,0 & 54,60 & 41,98 & 2,06 \\
\hline 2018 & 28 & 186412,7 & 121579,7 & 91584,9 & 5131,6 & 54,45 & 42,04 & 2,06 \\
\hline 2019 & 29 & 185284,1 & 121545,7 & 91575,1 & 5924,2 & 54,28 & 42,12 & 2,07 \\
\hline 2020 & 30 & 184202,0 & 121465,9 & 91576,6 & 5778,1 & 54,10 & 42,19 & 2,10 \\
\hline 2021 & 31 & 183164,8 & 121359,2 & 91589,2 & 5892,9 & 53,90 & 42,27 & 2,16 \\
\hline 2022 & 32 & 182171,0 & 121245,8 & 91612,3 & 6352,9 & 53,68 & 42,36 & 2,24 \\
\hline 2023 & 33 & 181218,7 & $121134 ? 0$ & 91645,2 & 7882,6 & 53,46 & 42,45 & 2,34 \\
\hline 2024 & 34 & 180306,2 & 121018,7 & 91687,3 & 8681,3 & 53,22 & 42,54 & 2,48 \\
\hline 2025 & 35 & 179431,7 & 120888,5 & 91737,9 & 7977,4 & 52,98 & 42,63 & 2,64 \\
\hline 2026 & 36 & 178593,2 & 120734,6 & 91796,4 & 9305,9 & 52,72 & 42,72 & 2,85 \\
\hline 2027 & 37 & 177788,8 & 120556,0 & 91862,1 & 10908,9 & 52,46 & 42,82 & 3,09 \\
\hline 2028 & 38 & 177016,6 & 120358,2 & 91934,3 & 15392,3 & 52,19 & 42,92 & 3,38 \\
\hline 2029 & 39 & 176274,8 & 120148,6 & 92012,5 & 17101,7 & 51,92 & 43,01 & 3,71 \\
\hline 2030 & 40 & 175561,5 & 119932,2 & 92096,1 & 22336,3 & 51,64 & 43,11 & 4,09 \\
\hline
\end{tabular}

Выводы. Статистическое моделирование позволяет дать прогнозы. При этом наиболее точные прогнозы на горизонт, равный основанию прогноза, получается при использовании волновых функций. Для итерации рекомендуется ежегодно проводить повторную идентификацию закономерностей.

\section{Список литературы}

1. Государственный (национальный доклад) о состоянии и использовании земель в Российской Федерации в 2011 году. М.: Федеральная служба государственной регистрации, кадастра и картографии, 2012. 248 с.

2. Мазуркин П.М. Коррелятивная вариация: учеб. пос. с грифомУМО РАЕ. Йошкар-Ола: Поволжский ГТУ, 2013. 120 с.

3. Мазуркин П.М., Касьянов Ю.В. Динамика управления земельным фондом субъекта федерации // Регистрация - кадастр. 2012. № 2. С.16-22.

4. Мазуркин, П.М. Закономерности простых чисел. - Германия: Palmarium Academic Publishing, 2012. - 280 c.

5. Мазуркин П.М., Филонов А.С. Математическое моделирование. Идентификация однофакторных статистических закономерностей: учебное пособие. Йошкар-Ола: МарГТУ, 2006. 292 с.

6. P.M. Mazurkin, "Wavelet Analysis of a Number of Prime Numbers." American Journal of Numerical Analysis, vol. 2, no. 2 (2014): 29-34. doi: 10.12691/ajna-2-2-1.

7. P.M. Mazurkin, "Stable Laws and the Number of Ordinary." Applied Mathematics and Physics, vol. 2, no. 2 (2014): 27-32. doi: 10.12691/amp-2-2-1. 